\section{Acolhimento e vínculo em uma equipe do Programa Saúde da Família}

\author{
Receptiveness and links to clients \\ in a Family Health Program team
}

Maria Denise Schimith 1,2

Maria Alice Dias da Silva Lima 3

\title{
Introdução
}

$14 \underline{a}$ Coordenadoria Regional de Saúde, Santa Maria, Brasil.

2 Centro Universitário

Franciscano,

Santa Maria, Brasil.

3 Escola de Enfermagem,

Universidade Federal

do Rio Grande do Sul,

Porto Alegre, Brasil.

Correspondência M. D. Schimith 4a Coordenadoria Regional de Saúde. Rua André Marques 675, Santa Maria, RS 97010-041, Brasil. madenise@terra.com.br

\section{Abstract}

This study analyzes the work by a Family Health Program (FHP) team, identifying the potential for developing receptiveness by the team and fostering links between the health professionals and clients. This was a case study with a qualitative approach. The data were collected through free observation, a semi-structured interview, and documents. A dialectic approach was used to analyze the material. A relationship was observed between the organization of the work process and the achievement of receptiveness and links to clients. There are gaps in receptiveness to health services clients, especially in the openness to demand, accountability for the population's health problems, and encouragement for client autonomy. Production of links is related to the development of clinical activities. According to FHP team members, health services clients are viewed alternately as subjects and objects. The principles and guidelines of the Unified National Health System (SUS) do not represent a project as conceived by the health professionals. The study concludes by proposing greater nursing staff involvement in clinical activities and receptiveness to users of the program.

Health Services Accessibility; Services Evaluation; Community Health Services; Basic Health Services
Acolhimento e vínculo dependem do modo de produção do trabalho em saúde 1 . $O$ acolhimento possibilita regular $\mathrm{o}$ acesso por meio da oferta de ações e serviços mais adequados, contribuindo para a satisfação do usuário. $O$ vínculo entre profissional/paciente estimula a autonomia e a cidadania, promovendo sua participação durante a prestação de serviço 2 .

Há uma relação entre acesso e acolhimento. Para Carvalho \& Campos 3 , acolhimento é um arranjo tecnológico que busca garantir acesso aos usuários com o objetivo de escutar todos os pacientes, resolver os problemas mais simples e/ou referenciá-los se necessário. A acolhida consiste na abertura dos serviços para a demanda e a responsabilização por todos os problemas de saúde de uma região. Prevê plasticidade, que é a capacidade de um serviço adaptar técnicas e combinar atividades de modo a melhor respondê-los, adequando-os a recursos escassos e aspectos sociais, culturais e econômicos, presentes na vida diária 2 . Ao sentir-se acolhida, a população procura, além dos seus limites geográficos, serviços receptivos e resolutivos 4 .

O acolhimento na saúde, para Bueno \& Merhy 5 , deve construir uma nova ética, da diversidade e da tolerância aos diferentes, da inclusão social com escuta clínica solidária, comprometendo-se com a construção da cidadania. O aco- 
lhimento deve resultar das relações no processo de atendimento, o que ocorre após ultrapassada a etapa do acesso. Nesse encontro entre profissionais e usuário, dá-se uma negociação visando a identificação de suas necessidades, uma busca de produção de vínculo, com o objetivo de lhe estimular a autonomia quanto à sua saúde 6 .

Segundo Campos 2, o vínculo com os usuários do serviço de saúde amplia a eficácia das ações de saúde e favorece a participação do usuário durante a prestação do serviço. Esse espaço deve ser utilizado para a construção de sujeitos autônomos, tanto profissionais quanto pacientes, pois não há construção de vínculo sem que o usuário seja reconhecido na condição de sujeito, que fala, julga e deseja. Merhy 7 afirma que a relação humanizada da assistência, que promove a acolhida, dá-se sob dois enfoques: o do usuário e o do trabalhador.

Matumoto 6 explica que o acolhimento é determinado pela concepção de ser humano e de saúde/doença em que o trabalho se baseia. Conclui que o porquê acolher desvenda o modo como se efetiva a implantação do Sistema Único de Saúde (SUS) e como os trabalhadores envolvidos "se posicionam frente ao lema 'Saúde como direito de todos e de cidadania', através dos princípios de universalidade, eqüidade, integralidade e acesso" 6 (p. 21).

Acolhimento e vínculo podem ser identificados no encontro do trabalhador com o usuário durante o trabalho vivo em ato. $\mathrm{O}$ trabalho vivo é o trabalho em ação, que está em processo de construção. Durante o trabalho vivo em ato, o trabalhador pode ser criativo e autônomo quanto aos instrumentos à sua disposição, dentro de um objetivo que se pretende atingir 8 .

Em 1994, o Ministério da Saúde propôs o Programa Saúde da Família (PSF) como uma estratégia para a reorientação do modelo assistencial, a partir da organização da atenção básica, apostando no "estabelecimento de vínculos e a criação de laços de compromisso e de coresponsabilidade entre profissionais de saúde e a população" 9 (p. 7). O PSF pretende trabalhar com o princípio da vigilância da saúde, com atuação inter e multidisciplinar, responsabilizando-se pela integralidade das ações na área de abrangência, ou seja, cada equipe, composta por, no mínimo, um médico, um enfermeiro, dois auxiliares de enfermagem e cinco a seis agentes comunitários de saúde, deve responder por uma população adscrita em torno de três mil pessoas.

Justifica-se analisar acolhimento e vínculo no PSF pela necessidade de se conhecer o que de fato ocorre durante a realização do trabalho em saúde, bem como apreender a intencionalidade do trabalhador por meio do projeto pensado, antes mesmo de sua execução.

Assim, surgem alguns questionamentos impulsionadores desta pesquisa: a relação entre usuários e profissionais no PSF proporciona acolhimento e vínculo? A autonomização do indivíduo está presente nessa relação? Os profissionais de saúde exercem seu autogoverno durante o trabalho vivo, de forma que o modo de produção possa ser modificado? Durante o encontro entre trabalhador e usuário ocorre uma negociação entre sujeitos para que sejam eleitas as necessidades de saúde?

Com base nesses questionamentos, o objetivo deste estudo foi analisar o trabalho de uma equipe de Saúde da Família, no que se refere ao acolhimento dos usuários e à produção de vínculo, durante o trabalho vivo em ato, procurando caracterizar o modo de produção de saúde que está sendo construído, bem como as concepções dos trabalhadores acerca do usuário do serviço.

\section{Metodologia}

Trata-se de uma pesquisa qualitativa, que se preocupa com a compreensão abrangente e profunda dos dados obtidos 10. Caracteriza-se como um estudo de caso. Os dados foram coletados no período de agosto a novembro de 2001, por meio de observação livre por amostragem de tempo, entrevista semi-estruturada 11 e consulta a documentos. Foram observadas, totalizando 54 horas e 15 minutos, jornadas de trabalho aleatórias dos membros de uma equipe de Saúde da Família de um município da 4a Coordenadoria Regional de Saúde, região administrativa do Estado do Rio Grande do Sul, Brasil. O grupo que participou da investigação compôs-se de um médico, uma enfermeira e três auxiliares de enfermagem.

O município escolhido está habilitado na Gestão Plena da Atenção Básica desde 1998, conforme a Norma Operacional Básica - NOB $01 / 96$. Possui uma população total de 16.403 habitantes, 8.209 na zona rural e 8.194 na urbana (http://tabnet.datasus.gov.br/cgi/deftohtm. exe?ibge/cnv.poprs.def, acessado em 30/Mai/ 2002). A equipe abrange 3.784 pessoas, 1.029 famílias cadastradas, o que corresponde a $45,00 \%$ da população urbana e $20,54 \%$ do total das famílias estimadas do município (http:// www.datasus.gov.br/siab/siabs.htm, acessado em 14/Jan/2002).

A análise dos dados foi realizada por intermédio de uma interpretação dialética, que re- 
vela o conteúdo intrínseco, conflitivo e antagônico da realidade 12 . Os passos utilizados foram: ordenação, classificação dos dados e análise final. Na fase de ordenação, procedeu-se à organização dos dados obtidos por meio das observações e das entrevistas. Para a classificação dos dados foi realizada a leitura exaustiva e repetida de todo o material empírico, destacando estruturas de relevância: acolhimento, acesso, responsabilização pelas necessidades do usuário, vínculo, estímulo à autonomia do usuário, concepção do usuário pelos trabalhadores, o trabalho da enfermeira e a implementação do SUS.

Consideraram-se as diretrizes para pesquisa com seres humanos para proteção dos direitos dos envolvidos na pesquisa, conforme os aspectos éticos apontados por Goldim 13 e pela Resolução 196/96 do Conselho Nacional de Saúde (Resolução no 196. Diário Oficial da União 1996; 10 out). Os profissionais aceitaram participar do estudo por meio do Termo de Consentimento Livre e Esclarecido.

Conservou-se o anonimato dos usuários envolvidos na observação, utilizando-se nomes fictícios. Portanto, não houve solicitação de consentimento de forma escrita. Quando o atendimento era a portas fechadas, o profissional solicitava a permissão para a nossa presença explicando que se tratava de uma pesquisa, e a pessoa podia optar por ser observada ou não.

\section{A organização do serviço de saúde e o processo de trabalho}

Analisamos o processo de trabalho da equipe, descrevendo o conjunto de atividades desenvolvidas, identificando as responsabilidades de cada trabalhador com ênfase no trabalho da enfermeira. Essa discussão faz-se necessária, pois o modo de organização entre os elementos que compõem o processo de trabalho é que conduz ao produto final e denota o projeto dos trabalhadores, revelando o espaço micropolítico do modelo de atenção que está se construindo 8 .

Identificamos alguns entraves no acolhimento à demanda e estabelecimento de vínculo com os usuários em função da organização do trabalho da enfermagem. Assim, destaca-se o papel do enfermeiro no processo de construção de um novo modo de agir em saúde pública, identificando seu espaço e revelando os benefícios que a população pode usufruir desse novo andar.

A enfermeira, nessa equipe, desenvolve prioritariamente atividades administrativas e educativas coletivas. Os momentos de encontro individual com os pacientes são escassos e foram observados somente durante a coleta de exames citopatológicos. Em alguns períodos, permanece na unidade e não atua diretamente em nenhuma das atividades em curso. Esse achado converge para os resultados já descritos por Almeida et al. 14, que classificaram 14,8\% do tempo da jornada da enfermeira como sem atividade. Confirmaram que a enfermeira realiza mais atividades administrativas do que de assistência de enfermagem. O potencial da enfermeira não está sendo plenamente utilizado nos serviços de saúde e ela vem executando ações do auxiliar de enfermagem.

Apesar da dedicação exclusiva ao PSF, a enfermeira não se constitui enquanto referência para as auxiliares. O profissional solicitado é o médico e não a enfermeira, mesmo para casos de sua competência. Teixeira \& Mishima 15, encontraram dados diversos no que se refere à presença da enfermeira na unidade.

A enfermeira escolhe desenvolver atividades de prevenção e promoção, em detrimento de ações clínicas, justificada pela dificuldade em garantir à população seu direito à assistência. Cecilio 16 diz que essa percepção faz parte de uma visão "purista" da realidade baseada na vigilância da saúde. Defendemos que a unidade básica deve ter suas funções ampliadas para atender integralmente os problemas de saúde de uma população, realizando, além da prevenção e promoção, atendimento clínico ampliado, garantindo os meios necessários à manutenção da vida.

Campos 17, quando discute a organização do processo de trabalho em equipes de saúde, propõe a possibilidade de se trabalhar com a noção de campo e núcleo de conhecimento. No campo teríamos os saberes e responsabilidades comuns a várias profissões e especialidades e, no núcleo, os específicos.

Mesmo em situações de necessidades compatíveis com o campo de conhecimento da enfermeira, a auxiliar não possui a opção "agendar para a enfermeira” no cardápio de ofertas. Exemplo disso é a coleta do teste do pezinho que é realizada pela auxiliar de enfermagem, restrita ao procedimento. A enfermeira poderia realizar uma consulta de puericultura, efetivando um acompanhamento dos recém-nascidos, otimizando a vinda da mãe e do bebê para a unidade. Nessa equipe o atendimento de puericultura é realizado pelo médico. A entrega de resultados de exames citopatológicos, mesmo os não alterados, são agendados para o médico. Assim, se esses atendimentos fossem realizados pela enfermeira, já seria possível diminuir a fila que é um fator de desumanização na relação com os usuários. 
Portanto, a demanda única para o médico, de atendimentos clínicos, contribui para a falta de acesso e para a vinculação dos usuários a um único membro da equipe. A pouca movimentação na unidade quando o médico está ausente, confirma esse achado, o que caracteriza o modelo médico hegemônico, conseqüência da organização do processo de trabalho que direciona a demanda clínica para o médico na unidade básica.

\section{Acolhimento e vínculo na produção do cuidado}

A atividade de recepção de um serviço de saúde deve ser entendida como um espaço no qual ocorre o reconhecimento das necessidades do usuário por meio da investigação, elaboração e negociação de quais serão atendidas 18. O que, nas palavras de Silva Jr. ${ }^{19}$, chamamos acolhimento, é uma ferramenta que estrutura a relação entre a equipe e a população e se define pela capacidade de solidariedade de uma equipe com as demandas do usuário, resultando numa relação humanizada.

As atividades de recepção nessa equipe são feitas, via de regra, pelas auxiliares de enfermagem, que seguem um cardápio preestabelecido de opções de encaminhamento, limitado pela capacidade tecnológica da unidade. Constatamos que a auxiliar de enfermagem utiliza o critério "não tem febre" ou "não tem vaga" para negar o acesso. Malta et al. 20 apontam para o acolhimento como a possibilidade de mudança do processo de trabalho a fim de atender a todos que procuram o serviço de saúde, ultrapassando portanto, o atendimento humanizado.

Observou-se o encaminhamento de usuários para o serviço de pronto-atendimento, ditado pela organização do trabalho e não pela necessidade do usuário. Esta conduta corresponde ao que Campos 2 e Cecílio 16 apontam como elementos que contribuem para a cristalização do imaginário popular, no qual o pronto-socorro é o local que resolve todos os problemas agudos. $\mathrm{O}$ acolhimento tem como objetivo resolver o que é de competência da rede básica, independente da hora de chegada na unidade.

A equipe também propicia aos seus usuários ações de desospitalização e ampliação da função da rede básica. São exemplos disso as cirurgias ambulatoriais e as internações domiciliares para casos de baixa complexidade. $\mathrm{O}$ projeto pensado por alguns membros da equipe é de resolver toda a demanda possível, tornando-se a porta de entrada do sistema. No entanto, o não-acesso pode ser observado pela fi- la para consulta médica, disputa no momento da distribuição das fichas e agenda médica lotada. A organização do processo de trabalho da equipe de PSF mantém o sistema de fornecimento de senhas para o acesso à consulta médica, o que também foi encontrado por Denti 21. Com isso pode-se afirmar que a estratégia do PSF vem mantendo a forma excludente de atendimento, no qual a prioridade é de quem chegar primeiro. Além disso, a população está sendo desumanamente tratada, tendo que enfrentar fila na madrugada. Este é o ponto mais importante que a utilização do acolhimento, enquanto ferramenta de organização do serviço, propõe reverter.

Teixeira 18 utiliza-se da expressão acolhimento-diálogo para distinguir recepção dos demais momentos de permanência do usuário na unidade.

Observa-se momentos de sensibilização da equipe a necessidades de usuários, mesmo com paciente fora da área de abrangência, realizando um acolhimento-diálogo e a criação de vínculo propondo o retorno como forma de diminuição do sofrimento. Essa ação reforça a teoria de Merhy 7 , que considera o acolhimento enquanto componente do processo de criação de vínculo e do processo terapêutico.

Há diferenças no acolhimento realizado pelas auxiliares, o que demonstra o autogoverno do trabalhador em saúde, justificado pelo jogo de subjetividades presentes nesses encontros. Esses achados concordam com Matumoto et al. 22, evidenciando que neste momento estão presentes as individualidades do trabalhador, com seus sentimentos e subjetividades objetivados no trabalho vivo em ato. Em alguns momentos, a relação torna-se mais humana e o procedimento centra-se na necessidade do usuário, em outros a ação volta-se somente ao procedimento.

Em alguns atendimentos, apesar da solicitação de informação do paciente, que demonstra sua necessidade de se tornar mais conhecedor da própria doença, a auxiliar não elege isso como necessidade de saúde.

Em duas oportunidades um mesmo paciente procura o serviço para controle da glicemia e da pressão arterial, e o encaminhamento final é o mesmo: procurar o médico. Ora, sabendo que, para conseguir consulta, o paciente tem de enfrentar a fila e que os serviços de saúde devem ter como princípio a eqüidade, a auxiliar não poderia se somar ao paciente nessa busca? Assim, tanto o usuário quanto o profissional terminam insatisfeitos; o primeiro por não ter sua necessidade atendida e o segundo por não se sentir autor desse processo. O pro- 
cesso de trabalho centrado no vínculo profissional/paciente garantiria o equilíbrio entre autonomia e responsabilização 17 .

Franco et al. 23 afirmam que a responsabilização clínica e sanitária e a ação resolutiva, com o objetivo de defender a vida das pessoas, só são possíveis quando se acolhe e vincula. Observamos situações contraditórias, indo do extremo de pleno abandono do usuário à sua própria sorte, a situações em que havia total responsabilização da equipe.

A noção de vínculo que o PSF implanta é a de conhecer as pessoas e seus problemas. O programa não se refere ao vínculo com a possibilidade de autonomização do usuário, nem com sua participação na organização do serviço.

$\mathrm{O}$ vínculo deve ser extensivo a toda a equipe de saúde, pois somente dessa maneira é possível atender de fato as demandas e necessidades dos sujeitos reais do trabalho em saúde. É necessário que o projeto de acolhimento e produção de vínculo seja um projeto de toda a equipe, a fim de que se concretize no trabalho vivo em ato. Para que isso ocorra a enfermeira deve tornar seu trabalho mais voltado para a clínica, valorizando o acolhimento e o vínculo com o usuário do serviço e tornandose um profissional com maior resolutividade.

\section{As concepções dos trabalhadores acerca dos serviços}

Analisar as representações que o trabalhador tem do usuário do serviço permite-nos conhecer como os profissionais se relacionam com seu objeto de trabalho, denotando o projeto pensado para a produção do cuidado. Esse conhecimento possibilita intervir na relação entre trabalhadores e usuários para tentar transformar os serviços em espaços de construção de sujeitos autônomos e criativos.

Identifica-se que existe um conceito predeterminado do usuário, definindo-o como portador de necessidades emocionais, ou seja, a somatização é a forma predominante do processo saúde-doença.

Um dos trabalhadores caracteriza os usuários que "batem ponto" no serviço como dependentes emocionais, sem questionar o porquê dessa atitude. É possível que suas necessidades de saúde não estejam sendo ouvidas e, portanto, não atendidas, por isso o retorno insistente. Além disso, aparece uma avaliação de que o sofrimento do usuário não é real, faz parte de sua fantasia, uma invenção para conseguir ser ouvido. Pitta 24, quando fala dos interesses em jogo na relação entre doente e cuida- dor, desafia-nos a buscar o ser humano existente no objeto de nosso cuidado, ao mesmo tempo genérico e singular. Genérico enquanto representação intelectual, e singular enquanto portador de necessidades, que se expõe a riscos, que sofre e produz sofrimento do seu jeito único.

Diante de uma situação de revolta do usuário devido à falta de medicamento, a auxiliar diz entendê-lo. No entanto, coloca-se numa posição de espectadora, quando afirma não ter nada a ver com o problema. Enquanto espectadora, não divide a responsabilidade e não reconhece os direitos dos cidadãos, tornando-os objetos. Essa situação corresponde ao que Pitta $24 \mathrm{diz}$ ao salientar que o doente que incomoda passa a ser objeto incômodo, mas ainda assim um objeto.

A integralidade do atendimento fica prejudicada quando não se considera o usuário enquanto sujeito, portador de direitos e de opções de vida. Por exemplo, a auxiliar identificou o uso de cigarro e bebida alcoólica como um quadro estático, não problematizando a situação de vida dos envolvidos. Assim, quando um usuário com hábitos insalubres utilizar o serviço, a visão que predominará será essa, tornando-se uma barreira na relação profissional/paciente.

A enfermeira diante de um paciente portador de uma doença terminal apóia-se na hipótese de que "não há mais nada a se fazer", tomando o usuário como um corpo que porta necessidades biológicas. Cecílio 25 (p. 116) diz que o usuário traz uma "cesta de necessidades de saúde" e cabe à equipe, com sensibilidade $\mathrm{e}$ preparo, desvendar para melhor atendê-lo.

Constatamos a indiferença da equipe diante do relato da Agente Comunitária de Saúde sobre um recém-nascido que ainda não realizou o teste do pezinho. A enfermeira diz que não tomará nenhuma atitude, pois a mãe tem responsabilidades com os filhos. O que se espera de um trabalhador de saúde, quando toma conhecimento de um problema, é que procure acolher de forma a responsabilizar-se pelas necessidades de saúde do paciente. Concordamos com Dussault 26 quando fala da situação desfavorável em que o doente se encontra em relação aos rumos de sua doença, não tendo condições, por falta de informação, de definir suas necessidades e como satisfazê-las.

Um trabalhador da equipe refere-se ao usuário como "teimoso". A visão de que o usuário deve cumprir o estabelecido pela equipe e de que são responsáveis pelas falhas do programa, leva-nos a questionar: será possível estabelecer vínculo enquanto o trabalhador necessitar 
da obediência do usuário? Ao concebermos o usuário enquanto sujeito, esse pode ser autônomo e julgar as orientações que há de respeitar.

Entretanto, a enfermeira considera também como trabalho da equipe a orientação dos direitos dos usuários, promovendo assim sua cidadania, e pode-se perceber que, quando as atividades são desenvolvidas pelas agentes comunitárias ou pela enfermeira, de fato existe participação da comunidade no planejamento das atividades.

\section{Modo de produção no PSF e a implementação do SUS}

O PSF, como uma proposta de estratégia de mudança do modelo de atenção que tem como objetivo a implantação do SUS, tem recebido várias críticas, principalmente no que tange à sua incapacidade de enfrentamento do modelo neoliberal $2,27,28$.

Campos 29 considera quase impossível implantar um modelo de saúde sem o acordo e o empenho da maioria dos trabalhadores e gerentes em consolidá-lo. Baseados nisso, analisou-se a posição que os trabalhadores assumem na discussão sobre a efetivação dos princípios do SUS.

Aparece a falta de estrutura e o distanciamento da Secretaria Municipal de Saúde prejudicando o andamento do atendimento, o que atinge sobretudo a população, já que é na individualidade do sujeito real que recaem os maiores prejuízos.

Observou-se a falta de medicação impossibilitando a continuidade do atendimento, e também que a equipe sente-se insatisfeita com essas condições de trabalho, revelando um sentimento de indignação quando se depara com o sofrimento do usuário e não consegue agir.

Parece já estar instituída a falta de medicação básica e exames laboratoriais. A opção dos usuários é pagar ou não fazer. Os usuários, ao se defrontarem com essa situação, ou se revoltam ou se resignam na sua condição de impotentes frente a isso. Bosi \& Affonso 30 encontraram resultados semelhantes e constataram que o que ocorre no cotidiano vai além da ausência de direitos, é a falta de direitos para uma boa parcela da população. Acreditamos que a opinião dos trabalhadores é formada a partir de vivência diária com os problemas de saúde, mas é preocupante ouvir sua opinião de que os usuários deveriam pagar pelos serviços, sabendo que a conquista do SUS, público e gratuito, foi conseguida graças ao esforço de vários atores sociais, entre eles os próprios trabalhadores.
A falta de acesso nos remete às várias discussões a que temos assistido e que são generalizadas como demanda reprimida. Enquanto quem está de frente para os problemas, os trabalhadores, não sentirem isso como direito da população e trouxerem à tona junto às instâncias do poder, será difícil incluir alguma estratégia que reverta esse quadro.

No entanto, a instância que se tenta convencer é outra, o usuário. Ao considerar o município como colaborador do SUS e não como parte efetiva do sistema, a enfermeira tenta convencer a população de que deve colaborar porque o SUS não cobre os custos. O verdadeiro papel do trabalhador nesse sentido seria a construção da cidadania estimulando as pessoas a participar do Conselho Municipal de Saúde e lutar por seus direitos com o acompanhamento da equipe.

Existe um espaço aberto de possibilidades na construção do sistema de saúde: que os atores sociais sintam-se no direito de desejar a mudança e que consigam visualizar a concretude da proposta. Para que isso ocorra é preciso que os trabalhadores de saúde desejem o SUS enquanto projeto de defesa da vida da população e não tomem os serviços de saúde como fonte de sofrimento. Quando os sujeitos trabalhadores se sentirem atores na busca desse projeto, é possível que avancemos em direção à implementação de um sistema legal e, acima de tudo, cidadão.

\section{Considerações finais}

A possibilidade de analisar o trabalho de uma equipe de PSF, no que tange ao acolhimento e vínculo, revelou a forma de produção de saúde como resultante da articulação dos elementos que compõem o processo de trabalho e permitiu identificar a participação da equipe no projeto de construção do SUS.

A relação entre a organização do processo de trabalho da equipe e a falta de acesso da população ao atendimento clínico foi um achado importante. A realidade da população adscrita é o atendimento centrado no médico e a manutenção das filas em horários desumanos para a garantia de acesso. Isso possibilita afirmar que não basta aumentar o número de equipes de Saúde da Família sem abrir espaços para novas formas de organização no processo de trabalho.

O processo de trabalho deve ser acordado entre os membros da equipe, definindo-se campo e núcleo de competência de cada profissional, com o objetivo de acolher e produzir vín- 
culo com os usuários. A atividade de acolhimento deve ser de responsabilidade de toda a equipe.

Identificou-se uma relação entre a produção de vínculo e o atendimento clínico com continuidade. Considerando que a atividade clínica aumenta a possibilidade de vínculo, assim como a responsabilização com as necessidades do paciente, sugerimos a aproximação da enfermeira a essas atividades, a fim de que suas ações tenham mais impacto na saúde da população, produzindo cuidados resolutivos.

A análise do espaço interno do serviço em questão permitiu compreender que a mudança do modelo assistencial relaciona-se muito com os espaços micropolíticos de uma organização em saúde, portanto, somente a sigla PSF não significa necessariamente mudança. Podemos constatar que se mantém a organização por ações programáticas e que, do modelo de vigilância à saúde, somente se retira a proposta de território delimitado e população adscrita.

Os princípios, diretrizes e a composição do SUS não são compreendidos e tampouco defendidos por toda a equipe de saúde. Não está cla-

\section{Resumo}

Analisa-se o trabalho de uma equipe do Programa Saúde da Família, identificando o potencial de acolhimento e de construção de vínculo entre profissionais e usuários. É um estudo de caso, com abordagem qualitativa. Os dados foram coletados por meio de observação livre, entrevista semi-estruturada e consulta a documentos. Para análise do material obtido, utilizou-se abordagem dialética. Verificou-se uma relação entre a organização do processo de trabalho e a possibilidade de concretização de acolhimento e vínculo. Existem lacunas no acolhimento aos usuários, sobretudo no que se refere à abertura do serviço para a demanda, à responsabilização pelos problemas de saúde da população e ao estímulo à autonomia do usuário. Constatouse que a produção de vínculo está relacionada com o desenvolvimento de atividades clínicas. O usuário do serviço, na concepção dos trabalhadores, é tido, por vezes, como sujeito e, por outras, como objeto. Os princípios e diretrizes do Sistema Único de Saúde não se constituem enquanto projeto pensado dos trabalhadores. Propõe-se a aproximação da enfermeira a atividades clínicas e ao acolhimento aos usuários.

Acesso aos Serviços de Saúde; Avaliação dos Serviços; Assistência à Saúde Comunitária; Serviços Básicos de Saúde ro, para os profissionais, a ligação entre o PSF e a efetivação do SUS. O desafio de construção do SUS deve ser assumido por todos os trabalhadores, caso contrário não o implementaremos.

Gostaríamos de destacar a característica de programa focal dirigido a classes menos favorecidas. Podemos afirmar que essa característica se apresenta de modo provisório e insuficiente, em termos de estrutura física, como a equipe vem trabalhando. A limitação imposta à equipe permite-nos dizer que o imaginário que a sustenta é de que o PSF é para os excluídos e que, portanto, dispensa maiores investimentos.

O PSF foi implantado com o objetivo de reorientar o modelo assistencial, descentralizar a gestão da saúde e efetivar o SUS. No entanto, a organização do processo de trabalho da equipe, a relação com os usuários nessa construção e, principalmente, o desafio de trabalhar com equilíbrio entre autonomia e responsabilidade, não estão sendo pautados no processo de implantação do PSF, seja pelos gestores, seja pelos trabalhadores.

\section{Colaboradores}

M. D. Schimith e M. A. D. S. Lima participaram conjuntamente da concepção do artigo, da análise nele contida, do atendimento às sugestões dos revisores e da revisão do texto final.

\section{Referências}

1. Merhy EE, Chakkour M, Stéfano E, Santos CM, Rodrigues RA, Oliveira PCP. Em busca de ferramentas analisadoras das tecnologias em saúde: a informação e o dia-a-dia de um serviço, interrogando e gerindo trabalho em saúde. In: Merhy EE, Onocko R, organizadores. Agir em saúde: um desafio para o público. São Paulo: Editora Hucitec; 1997. p. 113-50.

2. Campos GWS. Considerações sobre a arte e a ciência da mudança: revolução das coisas e reforma das pessoas. O caso da saúde. In: Cecilio LCO, organizador. Inventando a mudança na saúde. 2a Ed. São Paulo: Editora Hucitec; 1997. p. 29-87.

3. Carvalho SR, Campos GWS. Modelos de atenção à saúde: a organização de equipes de referência na rede básica da Secretaria Municipal de Saúde de Betim, Minas Gerais. Cad Saúde Pública 2000; 16:507-15. 
4. Ramos DD, Lima MADS. Acesso e acolhimento aos usuários em uma unidade de saúde de Porto Alegre, Rio Grande do Sul, Brasil. Cad Saúde Pública 2003; 19:27-34.

5. Bueno WS, Merhy EE. Os equívocos da NOB 96: uma proposta em sintonia com os projetos neoliberalizantes? http://www.datasus.gov.br/cns/ temas/NOB96/NOB96crit.htm (acessado em 14/ Fev/2002).

6. Matumoto S. O acolhimento: um estudo sobre seus componentes e sua produção em uma unidade da rede básica de serviços de saúde [Dissertação de Mestrado]. Ribeirão Preto: Escola de Enfermagem de Ribeirão Preto, Universidade de São Paulo; 1998.

7. Merhy EE. Em busca da qualidade dos serviços de saúde: os serviços de porta aberta para a saúde e o modelo tecno-assistencial em defesa da vida (ou como aproveitar os ruídos do cotidiano dos serviços de saúde e colegiadamente organizar o processo de trabalho na busca da qualidade das ações de saúde.) In: Cecilio LCO, organizador. Inventando a mudança na saúde. 2ạ Ed. São Paulo: Editora Hucitec; 1997. p. 117-60.

8. Merhy EE. Em busca do tempo perdido: a micropolítica do trabalho vivo em ato. In: Merhy EE, Onocko R, organizadores. Agir em saúde: um desafio para o público. São Paulo: Editora Hucitec; 1997. p. 71-112.

9. Secretaria de Assistência à Saúde, Ministério da Saúde. Saúde da Família: uma estratégia para a reorientação do modelo assistencial. Brasília: Secretaria de Assistência à Saúde, Ministério da Saúde; 1997.

10. Minayo MCS, organizador. Pesquisa social: teoria, método e criatividade. 7a Ed. Petrópolis: Editora Vozes; 1997.

11. Triviños ANS. Introdução à pesquisa em ciências sociais: a pesquisa qualitativa em educação. São Paulo: Editora Atlas; 1987.

12. Minayo MCS. O desafio do conhecimento: pesquisa qualitativa em saúde. 3a Ed. São Paulo/Rio de Janeiro: Editora Hucitec; 1994.

13. Goldim JR. Pesquisa em saúde: leis, normas e diretrizes. 2a Ed. Porto Alegre: Hospital das Clínicas de Porto Alegre; 2000.

14. Almeida MCP, Mishima SM, Silva EM, Mello DF. O trabalho de enfermagem e sua articulação com o processo de trabalho em saúde coletiva - rede básica de saúde. In: Almeida MCP, Rocha SMM, organizadores. O trabalho de enfermagem. 1a Ed. São Paulo: Cortez Editora; 1997. p. 61-112.

15. Teixeira RA, Mishima SM. Perfil dos trabalhadores no Programa Saúde da Família. Rev Bras Enferm 2000; 53:386-400.

16. Cecilio LCO. Modelos tecno-assistenciais em saúde: da pirâmide ao círculo, uma possibilidade a ser explorada. Cad Saúde Pública 1997; 13:469-78.
17. Campos GWS. Subjetividade e administração de pessoal: considerações sobre modos de gerenciar o trabalho em equipes de saúde. In: Merhy EE, Onocko R, organizadores. Agir em saúde: um desafio para o público São Paulo: Editora Hucitec; 1997. p. 229-66.

18. Teixeira RR. Agenciamentos tecnosemiológicos e produção de subjetividade: contribuição para o debate sobre a trans-formação do sujeito na saúde. Ciênc Saúde Coletiva 2001; 6:49-61.

19. Silva Jr. AG. Modelos tecnoassistenciais em saúde: o debate no campo da Saúde Coletiva. São Paulo: Editora Hucitec; 1998.

20. Malta DC, Ferreira LM, Reis AT, Merhy EE. Mudando o processo de trabalho na rede pública: alguns resultados da experiência em Belo Horizonte. Saúde Debate 2000; 24:21-34.

21. Denti IA. Serviços de saúde: reestruturação. Erechim: EdiAPES; 2001.

22. Matumoto S, Mishima SM, Pinto IC. Saúde coletiva: um desafio para enfermagem. Cad Saúde Pública $2001 ; 17: 233-41$.

23. Franco TB, Bueno WS, Merhy EE. O acolhimento e os processos de trabalho em saúde: o caso de Betim, Minas Gerais, Brasil. Cad Saúde Pública 1999; 15:345-53.

24. Pitta AMF. A equação humana no cuidado à doença: o doente, seu cuidador e as organizações de saúde. Saúde Soc 1996; 5:35-60.

25. Cecilio LCO. As necessidades de saúde como conceito estruturante na luta pela integralidade e eqüidade na atenção em saúde. In: Pinheiro R, Mattos RA, organizadores. Os sentidos da integralidade na atenção e no cuidado à saúde. Rio de Janeiro: Instituto de Medicina Social, Universidade do Estado do Rio de Janeiro/ABRASCO; 2001. p. 113-26.

26. Dussault G. A gestão dos serviços públicos de saúde: características e exigências. Revista de Administração Pública 1992; 26:8-19.

27. Franco TB, Merhy EE. PSF: contradições de um programa destinado à mudança do modelo assistencial. In: Mehy EE, Magalhães Jr. HM, Rimoli J, Franco TB, Bueno WS, organizadores. O trabalho em saúde: olhando e experienciando o SUS no cotidiano. São Paulo: Editora Hucitec; 2003. p. 55124.

28. Soares LT. As atuais políticas de saúde: os riscos do desmonte neoliberal. Rev Bras Enferm 2000; 53 Suppl:17-24.

29. Campos GWS. A saúde pública e a defesa da vida. 2a Ed. São Paulo: Editora Hucitec; 1994.

30. Bosi MLM, Affonso KC. Cidadania, participação popular e saúde: com a palavra, os usuários da Rede Pública de Serviços. Cad Saúde Pública 1998; 14:355-65.

Apresentado em 13/Out/2003

Versão final reapresentada em 22/Abr/2004 Aprovado em 24/Jun/2004 